\title{
Fallecimiento de dos personalidades del Movimiento
}

Con profunda tristeza, el CICR recibió la noticia de la muerte, el 24 de septiembre de 1988, del general Pietro Verri, presidente del Comité de Florencia de la Cruz Roja Italiana, y de la defunción, el 16 de octubre de 1988, del señor Soehanda Ijas, copresidente de la Cruz Roja Indonesia.

Ex vicecomandante de «l'Arma de Carabinieri», el general Verri se dedicó sin descanso a la causa de la Cruz Roja y del derecho internacional humanitario. Experto en la materia y miembro de la delegación italiana en la Conferencia Diplomática que culminó, en 1977, con la aprobación de los Protocolos adicionales a los Convenios de Ginebra de 1949, fue, con sus numerosos trabajos y traducciones al italiano, un gran promotor de la difusión del DIH en su país, conjugando con éxito dos grandes cualidades: conocía perfectamente las cuestiones teóricas que plantea el derecho de los conflictos armados y, por otra parte, tenía una vasta experiencia de los problemas prácticos que suscita la aplicación de esas normas. Se encargó asimismo de dirigir, durante varios años, los cursos de formación para educadores de derecho humanitario en la Cruz Roja Italiana, así como de la enseñanza sistemática del derecho de los conflictos armados en la Escuela de Guerra Aérea y en la Escuela de Oficiales de Carabineros.

Como presidente — de 1980 a 1986- de la Comisión Académica sobre las Instrucciones Militares, aportó una valiosa contribución a las actividades del Instituto Internacional de Derecho Humanitario de San Remo, del que fue miembro desde 1972.

El CICR mantuvo una estrecha colaboración con el general Verri en el ámbito del derecho internacional humanitario. Recientemente, el general autorizó al CICR a publicar una versión francesa de su «Dizionario di diritto internazionale dei conflitti armati», obra muy completa y práctica, en la que se definen los principales conceptos de las dos ramas del derecho internacional: el jus ad bellum y el jus in bello. 
El señor Soehanda Ijas, que había sido secretario general de la Cruz Roja Indonesia de 1966 a 1986, contribuyó ampliamente al desarrollo de la Sociedad Nacional tanto en el plano nacional como internacional. Era miembro de la Comisión sobre la Cruz Roja, la Media Luna Roja y la Paz, así como del Grupo de Trabajo sobre la Revisión de los Estatutos de la Cruz Roja Internacional y del Acuerdo entre el CICR y la Liga. De 1981 a 1986, fue miembro de la Comisión Permanente de la Cruz Roja.

El CICR guardará un emocionado recuerdo de esos grandes servidores de la causa humanitaria. 